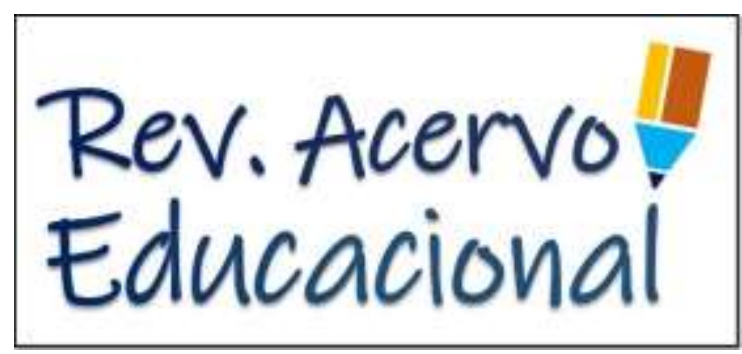

REVISÃO BIBLIOGRÁFICA

Recebido em: 10/2019

Aceito em: $11 / 2019$

Publicado em: 12/2019

\title{
Desafios dos alunos com deficiência auditiva no ensino regular
}

\author{
Challenges of hearing-impaired students in mainstream education \\ Desafíos de los estudiantes con discapacidad auditiva en la educación general \\ Célia Regina Fonseca ${ }^{1}$, Julyanne Pereira Neto², Silvera Nunes Gomes ${ }^{3}$.
}

\begin{abstract}
Resumo
Este trabalho versa sobre os desafios da inclusão educacional de alunos com deficiência auditiva no ensino regular. Faz uma reflexão referente as dificuldades que os professores têm mediante as suas ações e suas didáticas em salas regulares a assegurarem a inclusão desses alunos nesse contexto como forma de adotar uma educação inclusiva no processo de ensino, havendo assim a necessidade de um profissional capacitado que lhes auxiliem nessa ação, o intérprete, ou que haja políticas públicas que englobem a capacitação dos profissionais da educação para que se sintam preparados em sala de aula para receber esses referidos alunos. O objetivo dessa pesquisa é de analisar as políticas educacionais mediante ao processo de inclusão do aluno surdo nas escolas regulares. Fazer uma reflexão sobre a inclusão ou exclusão desses alunos dentro da escola, ou se de fato recebem toda a assistência prevista por lei. A metodologia abordada consiste em pesquisa bibliográfica.
\end{abstract}

Palavras-chave: Educação Inclusiva, Deficiência auditive, Escola regular.

\begin{abstract}
Abstrat
This paper addresses the challenges of educational inclusion of students with hearing impairment in mainstream education. Reflects on the difficulties that teachers have through their actions and didactics in regular classrooms to ensure the inclusion of these students in this context as a way to adopt an inclusive education in the teaching process, thus having the need for a qualified professional who can assist in this action, the interpreter, or that there are public policies that include the training of education professionals to feel prepared in the classroom to receive these students. The objective of this research is to analyze educational policies through the process of inclusion of deaf students in regular schools. Reflect on the inclusion or exclusion of these students within the school, or whether they receive all assistance provided by law. The approached methodology consists of bibliographic research.
\end{abstract}

Keywords: Inclusive Education, Hearing deficiency, Regular school.

\section{Resumen}

Este documento aborda los desafíos de la inclusión educativa de los estudiantes con discapacidad auditiva en la educación general. Reflexiona sobre las dificultades que los maestros tienen a través de sus acciones y didácticas en las aulas regulares para garantizar la inclusión de estos estudiantes en este contexto como una forma de adoptar una educación inclusiva en el proceso de enseñanza, teniendo así la necesidad de un profesional calificado que pueda ayudar en esta acción, al intérprete, o que existen políticas públicas que incluyen la capacitación de profesionales de la educación para sentirse preparados en el aula para recibir a

\footnotetext{
${ }^{1}$ Professora do estado de Juazeiro- BA. E-mail: ailec.jesus@hotmail.com

${ }^{2}$ Trabalha na FAESPE- Faculdade de Educação Superior de Pernambuco- Petrolina-PE.

${ }^{3}$ Professora Rede Municipal de Petrolina -PE.
} 
estos estudiantes. El objetivo de esta investigación es analizar las políticas educativas a través del proceso de inclusión de estudiantes sordos en las escuelas regulares. Reflexione sobre la inclusión o exclusión de estos estudiantes dentro de la escuela, o si realmente reciben toda la asistencia provista por la ley. La metodología abordada consiste en investigación bibliográfica.

Palabras clave: Educación inclusiva, Pérdida de audición, Escuela regular.

\section{INTRODUÇÃO}

A educação inclusiva é uma modalidade de educação que coloca os educandos que possuem alguma deficiência ou qualquer transtorno psicológico em turmas regulares de ensino, na perspectiva de uma aprendizagem conjunta. É uma política de igualdade de direitos e respeito às diferenças. A educação como bem público e direito social é dever do Estado de garantir amplas possibilidades de oferta de educação de qualidade a todas as camadas sociais (DIAS SJ, 2009). Entretanto, precisamos compreender as mudanças que as políticas públicas de educação inclusiva promoveram para identificar os avanços e recuos presentes no sistema educativo contemporâneo.

A Lei Diretrizes e Base da Educação (LDB 9394/96) traz essa integração escolar com alunos com necessidades especiais. Mas, será que na prática isso realmente funciona? As escolas estão preparadas para a inclusão? Os professores possuem formação suficiente para integrar esses alunos nas salas regulares? Neste contexto, o Brasil também tem definido políticas públicas e criado instrumentos legais de uma educação para todos. Como cita a Lei 10.436/02, LIBRA foi reconhecida e oficializada como língua no território brasileiro, uma vez que o uso de LIBRAS permite ao indivíduo surdo uma melhor inclusão na sociedade, considerando que a língua de sinais é complexa, para compreensão podemos trazer a fala de Brito que revela sobre a "expressão de qualquer significado decorrente da necessidade comunicativa e expressiva do ser humano" (1998, p. 19).

A relevância do tema se deve ao fato de que, a questão da inclusão escolar de alunos surdos tem provocado reflexões a respeito de sua real viabilidade na escola regular sobre o processo de aprendizagem e desenvolvimento desses indivíduos. Para sustentar essa base podemos perceber na fala de (LACERDA CBF, 2006, p.03) quando ela diz que "A inclusão escolar é vista como um processo dinâmico e gradual, que pode tomar formas diversas a depender das necessidades dos alunos"

A metodologia utilizada foi de caráter bibliográfico com análise de dissertações, buscas de materiais acadêmicos, consultas pela Scielo e periódico. A partir daí, buscou-se conhecer a cerca de alguns conceitos pertinentes para uma melhor compreensão do tema abordado. Os principais autores estudados para a escrita desse material foram Brasil (1996), Carvalho (2016), Barreto (2014), Soares (2008) entre outros.

A pesquisa está assim constituída: A política da educação inclusiva ficando nas políticas educacionais de inclusão, ou seja, a busca de uma educação para todos de forma igualitária, bem como uma escola inclusiva norteando os parâmetros necessários a educação inclusiva dentro da escola. Pretende-se com esta pesquisa dar subsídios teóricos aos profissionais da educação, ou não, que trabalham com crianças com surdez contribuindo para a aprendizagem, o desenvolvimento e, consequentemente, para a inclusão escolar e social dessas crianças no ensino regular.

O objetivo dessa pesquisa é de analisar as políticas educacionais mediante ao processo de inclusão do aluno surdo nas escolas regulares de ensino. Visto que visa com isso refletir as questões que envolvem a inclusão de discentes com deficiência auditiva nas escolas regulares, trazendo um entendimento melhor sobre as políticas que norteiam e orientam a educação inclusiva.

\section{REVISÃO BIBLIOGRÁFICA}

Este artigo utilizou-se somente a pesquisa bibliográfica. Sobre esse tipo de pesquisa Marconi e Lakatos nos diz que a pesquisa bibliográfica ou de fonte secundaria, "abrange toda bibliografia já tornada pública em relação ao tema de estudo, desde as publicações avulsas até os meios de comunicações orais". (MARCONI 
MA; LAKATOS EM, 2018, p. 63). Diante do estudo realizado perante as teorias foi se produzido o estudo acerca da garantia das políticas públicas para alunos surdos na rede regular de ensino. Desta forma a pesquisa bibliográfica não representa uma mera repetição dos fatos mais propicia uma visão nova para os fatos.

Neste sentido "o reforço paralelo na análise de suas pesquisas ou manipulação de suas informações" (TRUJILLO F, 1974, p. 230), o que permite no artigo visualizar informações que leva a uma reflexão sobre o processo de inclusão dos alunos surdos dentro das escolas regulares e a relevância da capacitação dos professores para os receberem ou da importância de se ter disponível um profissional capacitado que lhes auxiliem na sala regular. De modo geral esta pesquisa também se utilizou de fontes secundária, isso porque as pesquisas bibliográficas são caracterizadas como sendo fontes secundárias. Ou seja, o material pesquisado surgiu de livros publicados, acervos, artigos, revistas e jornais científicos caracterizando então como fontes secundárias.

\section{Política da educação inclusiva}

A educação inclusiva compõe um paradigma educacional baseado na concepção de direitos humanos, da valorização do ser humano onde prevalece à ideia de equidade, sem nenhum tipo de preconceito. $A$ inclusão escolar, como declara (BUDEL GC; MEIER M, 2012), implica em fazer com que a criança com deficiência se sinta como sendo uma parte do meio em que está inserida. Sendo assim, todos, sem exceção, participam do processo de aprendizagem e das atividades educacionais propostas, contando com o apoio da escola, da equipe multidisciplinar, professores, família e comunidade.

Segundo (MARQUES R, 2001 apud DESSEN, POLONIA 2007, p. 6) afirma que a função da escola no século XXI tem como objetivo precípuo o de estimular o potencial do aluno, levando em consideração as diferenças socioculturais em prol da aquisição do seu conhecimento e desenvolvimento global. Logo, depende das transformações das práticas e das políticas vigentes na escola e nos sistemas de ensino.

Segundo a Declaração Universal dos Direitos Humanos, da ONU, 1948 Os direitos humanos nascem da necessidade sociais e individuais inerentes a dignidade humana. A diferenciação funcional permite, mediante a especificação de problemas sociais e códigos da comunicação voltados para sua solução da situação preexistente. Com isso a sociedade ganha a liberdade de praticar seus direitos em todas as esferas sem preconceitos e violação de seus direitos.

O conceito de política no contexto educacional é monitorado e controlado pelo sistema. É dada a escola uma autonomia que na verdade ela não tem. Há um domínio por parte dos órgãos interessados em controlar a educação. Para (CARVALHO JD, 2016, p. 01) "A análise das políticas públicas traz importantes contribuições para a compreensão do funcionamento das instituições políticas e de como estas lidam com as complexidades da realidade social na atualidade". Dessa forma, a política pública voltada para a inclusão só se torna sólida e sustentável com ações consecutivas pautadas a cada uma das seguintes dimensões: políticas públicas, gestão escolar, estratégias pedagógicas, famílias e parcerias. Porém, falta, nesse contexto, esse envolvimento. Quando nos referimos às políticas públicas educacionais, é fundamental considerar o papel do Estado, nesse processo. A educação inclusiva demanda e envolve a ação direta de diferentes atores e esferas sociais que se relacionam de modo interdependente, numa perspectiva de rede, "[...] compreender a surdez como diferença significa reconhecer politicamente essa diferença” (SKLIAR CB, 1997, p. 05/06).

Quando se trata de políticas públicas, estamos nos referindo ao conjunto de leis, diretrizes, onde abrange as instâncias legislativa, executiva e judiciária buscando concretizar o direito à educação inclusiva em um determinado país ou território. Assim, ao analisarmos as políticas públicas vigentes na atualidade a esse respeito, no Brasil estão estabelecidos a Política Nacional de Educação Especial na perspectiva da Educação Inclusiva (2008) Site externo e o Plano Nacional de Educação (2014) Site externo, além da Lei de Diretrizes e Bases da Educação Nacional (1996) Site externo. Essa legislação, originária de diferentes órgãos, estabelece as diretrizes que cada educador deve conhecer.

Em relação à gestão escolar, se refere às diversas etapas de planejamento e desenvolvimento das atividades de direção de uma instituição de ensino. Abrange a construção dos projetos político-pedagógicos, 
a elaboração dos planos de ação, a gestão dos processos internos da instituição e de suas relações com a comunidade. Esse conhecimento ajuda e muito nesse processo de inclusão, segundo (LUCK H, 2006) é preciso diante de uma gestão democrática implementar programas educativos com diretrizes democráticas, para contribuir de forma que priorize coletivamente todos as soluções de acordo com a problemática que cada ser apresente.

Já as estratégias pedagógicas são as ações voltadas para o ensino regular com abrangência e ações voltadas ao ensino e aprendizagem de todos incluindo também o processo avaliativo. É fundamental, sempre que possível, avaliar se essas estratégias estão dando certo ou não, podendo mudá-la a qualquer momento. O importante é que se atinja o objetivo desejado que é o processo de aprendizagem, (HOFFMANN J, 2014) presa por uma avaliação mediadora e observacionista, para ela o processo avaliativo deve acontecer de forma continua, na medida que o aluno vai desenvolvendo suas habilidades, o professor deverá estar atento para tal evolução de cada situação. Para a autora esse processo deve iniciar logo nos primeiros anos de escolaridade e deve perpassar por toda trajetória escolar percorrido pelo aluno.

Quanto ao envolvimento da família dos educandos com a escola, é de suma importância esse elo família e escola. São duas instituições que proporcionam o desenvolvimento essencial das crianças com deficiências para sua trajetória de vida e para sua constituição enquanto indivíduos autônomos. De acordo com (REGO TC, 2003 apud DESSEN, POLONIA, 2007, p. 5), "é nesse espaço físico, psicológico, social e cultural que os indivíduos processam o seu desenvolvimento global, mediante as atividades programadas e realizadas em sala de aula e fora dela". Dessa forma, ambas precisam uma da outra tanto para o planejamento escolar, discutindo dificuldades e potencialidades, quanto para o desenvolvimento das atividades escolares e análise das relações estabelecidas.

É fundamental romper com os preconceitos existentes e entender as potencialidades e capacidades existentes em cada indivíduo. E daí, procurar trabalhar e preparar esses indivíduos para o exercício laboral e para ser cidadã (o). Os princípios não são negociáveis. As atitudes sim, podem ser mudadas. Esse é o desafio. Os desafios aparecem nas relações entre pessoas diferentes convivendo no espaço comum. Fazer a escola para todos é aceitar o desafio de reinventar cotidianamente o mundo em que vivemos, Soares em sua frase que leva a reflexão do mecanismo de defesa do indivíduo diz que: "[...] leva à ferida identitária que não cicatriza" (SOARES EG, 2008, p. 13). O que Soares nos traz nessa frase é a certeza que é impossível esconder ou tirar algo que é seu, o que precisa é o respeito e a tolerância para que viva em uma sociedade sem enfrentamento de preconceitos.

\section{Escola inclusiva- parâmetros}

Conforme as Diretrizes Curriculares Nacionais, uma Escola Inclusiva para Educação Especial (MEC/SEESP, 1998), "implica uma nova postura da escola comum, que propõe no projeto político pedagógico, no currículo, na metodologia de ensino, na avaliação e na atitude dos educandos, ações que favoreçam a integração social e sua opção por práticas heterogenias".

"O currículo deveria ser adaptado às necessidades das crianças, e não vice-versa. Escolas deveriam, portanto, prover oportunidades curriculares que sejam apropriadas à criança com habilidades e interesses diferentes" (UNESCO, 1994, s/n)

Assim é válido ressaltar que um dos parâmetros necessários para a educação inclusiva é a capacitação dos discentes para trabalhar com esse alunado, a preparação e organização e adaptação da escola para oferecer uma educação de qualidade para todos, de modo inclusivo, para os alunos com necessidades especiais. Outro aspecto relevante diz respeito justamente à orientação do currículo e do projeto pedagógico, sendo esse crucialmente diferentes do ensino fundamental. "Na Educação Infantil, o foco do projeto está concentrado nas crianças, ao passo que no ensino fundamental ele ancora-se no conteúdo" (MAKIDADIONISIO C, MARTINS IC e GIMENEZ R, 2016). Nesse contexto, ressalta-se a importância de que as escolas regulares sejam orientadas sobre a educação inclusiva, com objetivo de constituir meios mais eficazes de combater atitudes discriminatórias ao criar uma comunidade acolhedora e construindo uma sociedade inclusiva e com educação para todos (SALAMANCA, 1994). 
O MEC estabelece como diretrizes da Educação Especial apoiar o sistema regular de ensino para a inserção dos portadores de deficiências, e dar prioridade ao financiamento de projetos institucionais que envolvam ações de integração. Isso está proposto na Política Nacional de Educação Especial elaborada em 1994 (MEC/SEESP, 1994). Esta mesma definição foi posteriormente reforçada na Lei de Diretrizes e Bases da Educação Nacional (Lei $n^{\circ}$. 9.394/96) e, mais recentemente nas Diretrizes Nacionais para a Educação Especial na Educação Básica.

Nas Diretrizes Nacionais para a Educação Especial na Educação Básica, Resolução CNE/CEB no 2/2001, no artigo 2º, há a seguinte orientação: "Os sistemas de ensino devem matricular todos os alunos [...] com necessidades educacionais especiais, assegurando as condições necessárias para uma educação de qualidade para todos" (BRASIL, 2001, p.19). Ou seja, cabe as escolas assegurar perante as leis os direitos do aluno deficiente, seja de natureza física, crônica, metal entre outras uma educação de qualidade, onde as mesmas em seu projeto político pensar em medidas que as inclua num currículo voltado para a educação inclusiva.

Essa educação inclusiva por sua vez, não deve acontecer de qualquer jeito, Para Freire, (1987, p.34), umas práxis educativas centradas nos valores e consciência, será capaz de libertar o homem de toda situação de opressão", podemos pegar essa fala de freire e refletir acerca do papel docente no enfretamento pela a garantia dos direitos dos alunos. Mas se o sistema educacional for modernizado, renovado, adaptado, abrangendo ações pedagógicas voltadas para esse aluno com necessidades especiais, poderá ser uma experiência exitosa. Pois a inclusão é desafiadora e os docentes devem fazer parte dessa mudança. E ainda: "De um modo geral ainda há uma espera deque o aluno com necessidades especiais desenvolva comportamentos sociais e acadêmicos próximos de seus pares sem deficiência". (BARRETO MA, 2014, p. 21).

As crianças e jovens com deficiência devem ter acesso às escolas regulares sim, adequadas, pois a escola é o principal meio capaz de combater as atitudes discriminatórias, tornando e construindo uma sociedade inclusiva e igualitária, e abrangendo a educação para todos, para o MEC " [...] a educação especial é uma modalidade de ensino que perpassa todos os níveis, etapas e modalidades, realiza o atendimento educacional especializado, disponibiliza os recursos e serviços e orienta quanto a sua utilização no processo de ensino e aprendizagem nas turmas comuns do ensino regular". Brasil (2008, p.07).

A Proposta de Diretrizes para a Formação de Professores da Educação Básica delineia as exigências que se colocam para o desempenho do papel docente frente às novas concepções de educação do mundo contemporâneo: Orientar e mediar o ensino para a aprendizagem dos alunos; responsabilizar-se pelo sucesso da aprendizagem dos alunos; assumir e saber lidar com a diversidade existente entre os alunos; incentivar atividades de enriquecimento curricular; elaborar e executar projetos para desenvolve conteúdos curriculares; utilizar novas metodologias, estratégias e material de apoio; desenvolver hábitos de colaboração e trabalho em equipe (MEC, 2000, p. 5).

Diante dessa realidade existente ainda em algumas redes estaduais, é que nos questionamos: Como podemos mudar nossos conceitos e nos aprimorar para o futuro? Algumas escolas contemporâneas estão adotando escolas inclusivas ou exclusivas? Uma das formas de reforçar a luta de inclusão de pessoas com deficiência auditiva e demais deficiências, poderia ser a inclusão dessas modalidades nas capacitações de professores, estaduais, municipais, e no ensino privado, fazendo parte assim da formação do professor. $\mathrm{Na}$ questão de contagem ou estimativa do público surdo a escola conduz uma necessidade especifica através da legislação, as instituições que recebem esses alunos são melhores preparados para atender e fornecer os atendimentos que os alunos buscam. (SALLES HMML,2004)

As escolas regulares, tem direito por lei, de receber materiais de apoio bem como intérpretes para trabalhar nas salas de atendimento educacional especializado (AEE), com os alunos com deficiência auditiva dando assim o suporte necessário para o seu desenvolvimento no processo de ensino e aprendizagem. Para isso, recomenda-se que a direção da escola entre em contato com a Secretaria de Educação responsável. Mas quando isso não acontece, o que fazer? De o Sistema não disponibiliza um intérprete, como trabalhar 
com esse aluno? É uma realidade presente em várias escolas ditas inclusas, mas não está preparada para certas situações. Como agir e a quem recorrer? Segundo (PAULON SMD, 2005) o fator primordial para que a educação inclusiva de certo é o investimento em capacitação para todos os profissionais que atuam com pessoas que possuam algum tipo de deficiência, e que somente o professor preparado e capacitado é capaz de resolver diferentes situações que envolva a missão de educar.

No cotidiano escolar, atitudes simples do professor em sala podem facilitar o aprendizado do aluno surdo. Para (DESSEN MA; POLONIA AC 2007) a escola tem a função social de preparar alunos, pais, professores para superarem as dificuldades, contribuindo para o processo de desenvolvimento do indivíduo. Segundo as autoras, o uso de estratégias deve estar adaptado a cada realidade, aos recursos disponíveis e às demandas da comunidade.

Assim, para o aluno com dificuldades auditivas, pode colocá-lo nas carteiras da frente para uma maior aproximação com o sujeito e o professor falar com clareza, para que ele possa fazer leitura labial ou orofacial no caso dos alunos que sabem fazê-lo. A utilização de recursos visuais nas aulas, como projeções e registros no quadro negro pode contribuir para aprendizagem. Há também o trabalho com alunos que já conhecem a Língua de Sinais e podem ajudar nesse processo. Mas para garantir um ensino mais eficaz é necessário o aprendizado de libras que deve ocorrer no contra turno, nas salas de AEE. "O AEE em seus três momentos visa oferece a esses alunos a oportunidade de demonstrarem se beneficiar de ambientes inclusivos de aprendizagem". (DAMÁZIO MFM; FERREIRA JP, 2010, p. 10)

A escola em seu pleno exercício deve por sua vez possuir um currículo inovador, multidisciplinar e inclusivo, assim a formação continuada dos seus docentes é de suma importância, porque uma vez capacitados para Ihe dar com situações inclusivas terão toda ferramenta para contribuir na aprendizagem dos alunos surdos. É de grande importância destacar que uma vez a escola apresentado um público que necessite desse atendimento, além das capacitações a presença do intérprete é relevante nesse processo. Em termos gerais, infelizmente vivemos algumas realidades em que isso não acontece e o aluno continua no seu mundo silencioso fazendo de conta que aprende, mas que na verdade não estão compreendendo absolutamente nada. (MILOVICH GT; BOUDREAU JW, 2000) trabalham também com essa linha de raciocínio, destacando a importância da busca pela capacitação profissional, visando a qualificação dos recursos humanos para atender a todos que buscam o conhecimento em instituição de apoio.

\section{CONSIDERAÇÕES FINAIS}

Este artigo desempenhou uma temática relevante a classe de alunos que possuem suas limitações referente a surdes. Trouxe aspectos legais que pontuam uma seguridade perante a lei sobre as políticas educacionais inclusivas dentro da escola regular. Sendo assim a inclusão no espaço escolar tem muitos aspectos que precisam ser considerados. Em contrapartida, existe grandes avanços nos espaços da rede de apoio (AEE), o qual percebe-se a afetividade, o compromisso, a dedicação e a concretização da proposta oferecida, promovendo a conscientização da escola inclusiva em relação à inclusão do aluno surdo, essas ações vem abrilhantar boas relações e a proposta prevista por lei de assegurar não somente aos alunos surdos a garantia da inclusão dos mesmos no meio educacional.

\section{REFERÊNCIAS}

1. BARRETO MA. BARRETO, FOC; Educação Inclusiva: contexto social e histórico, análise das deficiências e uso das tecnologias no processo de ensino-aprendizagem. 1. Ed. São Paulo: Érica, 2014.

2. BRASIL. Lei de Diretrizes e Bases da Educação Nacional. Lei 9.394, de 20 de dezembro de 1996. Diário Oficial da União, Brasília, 23 dez. 1996.

3. Política nacional de educação especial na perspectiva da educação inclusiva. Brasília, 2008. Disponível em: $<$ http://portal.mec.gov.br/arquivos/pdf/politicaeducespecial.pdf>. Acesso em: 08 nov. 2019

4. MEC, SEESP. Subsídios para organização e funcionamento de serviços de educação especial, Área de Altas Habilidades. v. 9, 1998 (Série Diretrizes) Brasil. 
5. BRITO LF. (org.). Educação Especial - Língua Brasileira de Sinais. V. III. Série Atualidades, no 4. Brasília: SEESP/MEC, 1998.

6. BUDEL GC, MEIER M. Mediação de aprendizagem na educação especial. Curitiba: Ibpex, 2012. (Série Inclusão Escolar).

7. CARVALHO JD. Políticas públicas e inclusão social no Brasil: um olhar sobre a educação superior. Revista Jus Navigandi. Publicado em jun. de 2016. Disponível em https://jus.com.br/artigos/49835/politicas-publicas-e-inclusaosocial-no-brasil-um-olhar-sobre-a-educacao-superior. Acesso em 08/09/2019 as $21 \mathrm{~h}$ e $17 \mathrm{~min}$.

8. DAMÁZIO MFM, ALVES CB; e FERREIRA JP. A Educação Especial na Perspectiva da Inclusão Escolar: abordagem bilíngue na escolarização de pessoas com surdez. Brasília: Ministério da Educação, Secretaria de Educação Especial; Fortaleza: Universidade Federal do Ceará, 2010.

9. DIAS SJ. Higher education: a public good, a State duty. In: POLAK, E.E et al. (Ed.). Public responsability for higher education. Paris: UNESCO, 2009.

10. DESSEN MA; POLONIA AC. A família e a escola como contextos de desenvolvimento humano. Ribeirão Preto: Paidéia. Vol. 17. n. 36. Jan/Abr. 2007. Disponível em: <http://ww.scielo.br/scielo.php?script=sci_arttext\&pid=S0103863X2007000100003>. Acesso em 10 set. 2019.

11. FREIRE P. Pedagogia do Oprimido. RJ. Ed. Paz e Terra, 1987.

12. GARCEZ L. Um histórico e as dimensões da educação inclusiva. Disponível em https://diversa.org.br/artigos/umhistorico-e-as-dimensoes-da-educacao-inclusiva/ Acesso em 08/09/2019.

13. HOFFMANN J. Avaliação: mito \& desafio: uma perspectiva construtivista. Editora Mediação, Porto Alegre 2014.

14. LACERDA CBF. A inclusão escolar de alunos surdos: o que dizem alunos, professores e intérpretes sobre esta experiência. Cad. CEDES vol.26 no.69 Campinas May/Aug. 2006.

15. LUCK H. Gestão participativa na escola. Petrópolis: Vozes, 2006.

16. MAKIDA-DIONÍSIO C; MARTINS IC e GIMENEZ R. Inclusão escolar: uma reflexão sobre a transição da educação infantil para o ensino fundamental. Comunicações, v.23, n.2, p. 207-224, 2016.

17. MARCONI MA; LAKATOS EM. Técnicas de pesquisas. 8. Ed. São Paulo: atlas, 2018.

18. MARQUES R. Professores, família e projecto educativo. Porto, PT: Asa Editores. (2001)

19. MILKOVICH GT; BOUDREAU JW. Administração de Recursos Humanos. 8 ed. São Paulo: Atlas, 2000.

20. PAULON SMD. Subsidiário da política de inclusãollSimone Mainieri Paulon Lia Beatriz de Lucca.Freitas, Gerson Smiech Pinho-Brasília: Ministério da Educação, Secretaria de Educação Especial, 2005. 48p

21. REGO T C (2003). Memórias de escola: Cultura escolar e constituição de singularidades. Petrópolis, RJ: Vozes.

22. SALAMANCA, Declaração. Sobre Princípios, Políticas e Práticas na Área das Necessidades Educativas Especiais. 1994. Disponível em: Acesso em: 07 nov. 2019.

23. SALLES HMML: Et Al. Ensino da Língua Portuguesa para surdos - caminho para prática pedagógica. Volume II. (Programa Nacional de Apoio à Educação dos Surdos). Brasília: MEC, SEESP, 2004.

24. SKLIAR CB. Um olhar sobre nosso olhar acerca da surdez e as diferenças. In: Skliar, C.B. (Org.) A surdez: um olhar sobre as diferenças. Porto Alegre: Mediação, 1998.

25. SOARES, EG. Do quilombo à escola: os efeitos nefastos das violências sociais silenciadas. Dissertação (Mestrado em Educação) - Faculdade de Educação, Universidade Federal do Paraná, Curitiba, 2008

26. TRUJILLO F. A metodologia das ciências. 3. Ed. Rio de janeiro: Kennedy, 1974. 